\title{
Endotracheal intubation in critically ill patients, practices, complications and factors associated with post intubation hypotension: a study in National Hospital Sri Lanka
}

\author{
Ruvini Jayanimali Kosgollawatta Walimanna Gamage ${ }^{1^{*}}$ \\ Locum consultant, ${ }^{1 *}$ Anaesthesia \& Intensive care, North Wick Park Hospital, United Kingdom.
}

\begin{abstract}
Context
Intubation in critical care setting is common and associated complication rates are high, up to $40 \%$. Complication rates differ from intensive care unit (ICU) to ICU as their guidelines and practices are different. Post induction hypotension $(\mathrm{PIH})$ is associated with increased mortality, morbidity and length of ICU stay.
\end{abstract}

\begin{abstract}
Objectives
Primary objective was to describe the practices, common induction agents, neuromuscular blocking agents used for intubation and to identify the common complications following intubation in critically ill patients in National Hospital Sri Lanka (NHSL). The secondary objective was to identify factors associated with post intubation hypotension in critically ill patients.
\end{abstract}

\begin{abstract}
Methodology
Descriptive cross -sectional study design with analytical component. Critically ill patients who were subjected to intubation outside theatre were the target population. Study was conducted in all ICUs, A\&Es and ward settings in NHSL. Data entered to IBM SPSS 20 version. Basic descriptive statistical analysis was done, and data was summarized using frequency percentages. In the analytical component, univariate analysis was performed on variables to find statistically significant risk-factors for development of PIH. Statistically significant riskfactors were subjected to multivariate analysis. Statistical associations were studied using regression co-efficient and chi-square test. $\mathrm{P}$ value $<0.05$ was taken as significant.
\end{abstract}

\section{Results}

Data from 150 intubations were analysed. Pre intubation cardiovascular (52\%) and respiratory support $(60 \%)$ was high. Majority $(60 \%)$ of intubations of critically ill was performed during daytime and in the ICUs (68\%). Commonly used induction agent was midazolam (58\%) and neuromuscular blocking agent (NMB) was suxamethonium (84\%). Supplemental fentanyl was used in $76 \%$ of cases. No failed intubation was recorded and $68 \%$ of time intubation was successful in the first attempt. Mechanical complications were low (6\%) each for oesophageal intubation and aspiration and regurgitation. Post intubation hypoxaemia was common (50\%). $\mathrm{PIH}$ was calculated as $26 \%$ according to definition (New or increased requirement of vasopressors within $60 \mathrm{mins}$ of intubation). After multivariate analysis, propofol induction (OR $17.38, \mathrm{P}$ value $=0.000)$, post intubation hypoxaemia $(\mathrm{OR} 3.3, \mathrm{P}$ value $=0.033)$, post intubation mechanical complications $(\mathrm{OR} 3.8, \mathrm{P}$ value $=0.000)$, suxamethonium $(\mathrm{OR} 0.09, \mathrm{p}$ value $=$ 0.003 ), pre intubation airway support (OR 0.012, $\mathrm{P}$ value $=0.000)$, pre intubation cardiovascular support (OR 0.025, $\mathrm{P}$ value $=0.000$, have shown association with PIH.

*Correspondence: Ruvini Jayanimali Kosgollawatta Walimanna Gamage

E mail: malikosgollawatta@yahoo.com

https://orcid.org/0000-0002-2639-5931

Received: 09/04/2020

Accepted: 21/05/2020

DOI: http:/doi.org/10.4038/slja.v28i2.8569

\section{Conclusion}

There is high success rate of intubation without any failed intubation during the study period in critically ill patients in NHSL. There is higher percentage (84\%) of involvement of formally trained doctors in the process of intubating critically ill. More than half of intubations are directly 
supervised by a senior doctor. Adherence to preoxygenation was high as $98 \%$ however inadequate usage of difficult airway trolley $(88 \%)$ and capnography $(68 \%)$ was observed. Even though the mechanical complication rates of intubations are low, there is high rates of post intubation hypoxia and hypotension. Usage of propofol as induction agent, post intubation hypoxaemia and mechanical complications were identified as significant risk factors for PIH. Pre intubation airway support, cardiovascular support and usage of suxamethonium had shown protective effect towards the development of PIH.

Keywords: Intubation; critically ill; practices; post intubation complications; post intubation hypotension; associated factors

\section{Introduction}

Intubation is a common occurrence in the intensive care setting. ${ }^{1}$ This is quite different and difficult when compared with an intubation of a patient in theatre for elective procedures due to presence of hypoxaemia, hypotension, confusion, agitation with low GCS. Critically ill patients are unable to tolerate induction agents and neuromuscular blocking medications as they have cardiac depressing effects and induces apnoea in already hypotensive and hypoxic patients. ${ }^{2}$ Complications depends not only on patient factors but also on the experience and competence of intubating doctor and dose and choice of induction and neuromuscular blocking agents. ${ }^{3,4}$

Complication rates are known to be as high as $40 \%$ and NAP4 study in UK showed one in four major airway event occurs in either intensive care units (ICU) or emergency department. ${ }^{4}$ Different ICUs have different complication rates as their emergency airway management differs from each other. ${ }^{2}$ Complications that commonly result from intubation in the critically ill include hypoxaemia, aspiration, hypotension, and cardiac arrest.

Though the information regarding airway complications are robust, the details on the haemodynamic compromise is limited. Post intubation hypotension (PIH) has shown to increase inICU mortality, length of stay and inhospital mortality. ${ }^{5,6.7}$ Identified risk factors for $\mathrm{PIH}$ were pre-intubation shock index, chronic kidney disease, intubation for acute respiratory failure, advancedage, intubation complications and usage of neuromuscular blockers. They were independently associated with the development of PIH. ${ }^{5,6.8 .9 .10}$

There are no studies done on this topic in NHSL and there is no documented guidance on the induction or NMB agents. Primary aim of this study was to describe the practices, common induction and NMB agents used for intubation in the critically ill patients in NHSL. Secondary aimwas to identify the complications and factors associated with post intubation hypotension in this group.

\section{Subjects and Methods}

This is a descriptive cross-sectional study with an analytical component. Institutional ethical committee approval was obtained, and patient consent was not considered as it is only documentation and analysis of existing practice. The critically ill patients (patients needing ICU care) who were subjected to intubation outside theatre were the target population.

Sample size for the study was calculated based on the following formula (Lowanga and Lames how 1991). $N=Z 2 * p(1-p) / d 2, N=$ sample size, $Z=Z$ value (corresponding to confidence level) $\mathrm{P}=$ Anticipated population proportion $\mathrm{d}=$ Absolute precision required for the estimate to fall within given percentage points of true proportion $\mathrm{D}=$ Design effect Considering a precision of $(\mathrm{d})=$ 0.07 , and expected prevalence of $(p)=0.2$ (put the reference of hypotension prevalence), confidence level $95 \%$ and design effect 1.2 a minimum sample size of 150 .

Critically ill adult patients ( $>$ 18yrs) who were intubated in non-theatre environments was included in the study while pregnant and postpartum patients were excluded. Data collection form was used and was filled by the doctor who had intubated the patient, after the intubation. Patients who fit the inclusion criteria were recruited for the study until the sample size (150) was reached.

There was no universal definition for post intubation hypotension. Few cohort studies have investigated this matter and found that immediate (within 60 minutes) post intubation requirement of vasopressors was the best predictor for in hospital mortality and ninety day mortality. ${ }^{7,10}$ 
Therefore for this study, new or increased vasopressor requirement within 60 minutes of post intubation was taken as definition of post intubation hypotension.

\section{Statistical analysis}

Data was entered to IBM SPSS 20 version. Basic descriptive statistical analysis done. The data were summarized using frequency percentages. In the analytical component, univariate analysis was performed on the variables to identify statistically significant risk factors for development of PIH. Some variables were made binary variables to get reasonable numbers for analysis without harming the accuracy of data. Patients were stratified to two groups depending whether they developed PIH or not. Risk factors that show a significant association for PIH were then subjected to multivariable logistic regression model. Statistical associations were studied using regression co-efficient and chi-square test. $\mathrm{P}$ value $<0.05$ was taken as significant.

\section{Results}

Highest percentage of patients ( $42 \%)$ were in the 46 to $60 \mathrm{yr}$ age group. Female to male ratio in this sample was $58 \%$ to $42 \%$.

Primary pre intubation disease distribution of the study population was trauma (30\%), respiratory failure $(20 \%)$, cardiac failure $(18 \%)$, cardiorespiratory (14\%), shock (14\%) and sepsis (8\%). $36 \%$ of patients had hypoxia, defined by saturation less than $88 \%$ while $30 \%$ were hypotensive. $58 \%$ of intubated patients had Glasgow Coma Scale of less than 12 before intubation.

Majority $(60 \%)$ of intubations took place at daytime and $68 \%$ of critically ill patients had undergone this procedure in ICUs. Twenty four percent of study sample was assessed to have difficult intubation, but only $10 \%$ of patients needed third attempt at intubation.

$70 \%$ of the time urgency of intubation was recorded as immediate. Adherence to preoxygenation was good $(98 \%)$. Availability of difficult intubation trolley and capnography for intubation was poor, $88 \%$ and $68 \%$ respectively.
Data on preparation and procedure of intubation documented in Table 1.

Table 1: Preparation and procedure

\begin{tabular}{|c|c|c|}
\hline Procedure & Number & Percentage \\
\hline Assessed difficult face mask ventilation & 33 & $22 \%$ \\
\hline Actual difficult bag and mask ventilation & 6 & $4 \%$ \\
\hline $\begin{array}{l}\text { Intubation on first attempt } \\
\text { Intubation on second attempt } \\
\text { Intubation on third attempt } \\
\text { Failed intubation }\end{array}$ & $\begin{array}{l}102 \\
33 \\
15 \\
0\end{array}$ & $\begin{array}{l}68 \% \\
22 \% \\
10 \% \\
0 \%\end{array}$ \\
\hline Assessed difficult intubation & 36 & $24 \%$ \\
\hline $\begin{array}{l}\text { Procedure } \\
\text { Laryngoscopy view at first attempt (Cormack- } \\
\text { Lehane) } \\
1 \\
2 \\
3 \\
4\end{array}$ & $\begin{array}{l}\text { Number } \\
\\
51 \\
69 \\
27 \\
3\end{array}$ & $\begin{array}{l}\% \\
\\
34 \% \\
46 \% \\
18 \% \\
2 \% \\
\end{array}$ \\
\hline $\begin{array}{l}\text { Time of intubation } \\
\text { Day } \\
\text { Night }\end{array}$ & $\begin{array}{l}90 \\
60\end{array}$ & $\begin{array}{l}60 \% \\
40 \%\end{array}$ \\
\hline $\begin{array}{l}\text { Location of intubation } \\
\text { ICU } \\
\text { Resuscitation room } \\
\text { Ward } \\
\text { ETU }\end{array}$ & $\begin{array}{l}102 \\
21 \\
18 \\
9\end{array}$ & $\begin{array}{l}68 \% \\
14 \% \\
12 \% \\
6 \%\end{array}$ \\
\hline $\begin{array}{l}\text { Urgency of intubation } \\
\text { Immediate } \\
\text { Urgent } \\
\text { Semi elective } \\
\text { Elective }\end{array}$ & $\begin{array}{l}72 \\
51 \\
24 \\
3\end{array}$ & $\begin{array}{l}48 \\
34 \\
16 \\
2\end{array}$ \\
\hline
\end{tabular}

The most common reason for intubation was clinical deterioration (80\%). Other reasons were change in existing ET tube (8\%), failed extubation and accidental extubation each accounting for $6 \%$.

Medication used for intubation is shown in Table 2. Induction agents were used in all intubations and most used agent was midazolam (58\%). NMB agent usage was recorded as $98 \%$. Atracurium was used in $14 \%$ of patients.

Table2: Medications used for intubation

\begin{tabular}{|l|l|l|}
\hline Name of the medication & Number & Percentage \\
\hline Induction agent & 150 & $100 \%$ \\
Propofol & 51 & $34 \%$ \\
$\begin{array}{l}\text { Non Propofol induction } \\
\text { Ketamine }\end{array}$ & 21 & $14 \%$ \\
Midazolam & 78 & $58 \%$ \\
\hline Neuromuscular blocking agent (NMB) & 147 & $98 \%$ \\
Suxamethonium & 126 & $84 \%$ \\
Atracurium & 21 & $14 \%$ \\
None & 3 & $2 \%$ \\
& & \\
\hline Opioid & 114 & $76 \%$ \\
Fentanyl & 36 & $24 \%$ \\
None & & \\
\hline
\end{tabular}


More than three quarter (84\%) of intubations were performed by trained anaesthetists and 78 out of 150 intubations were done under senior supervision.

Immediate complications (within 60 minutes) of intubation are shown in Table 3 . Half of the patients developed hypoxia $\left(\mathrm{S}_{\mathrm{P}} \mathrm{O} 2<88 \%\right)$ with $6 \%$ developing very severe hypoxia.

$46 \%$ patients developed post intubation low systolic blood pressure $(<90 \mathrm{mmHg})$. Thirty-nine patients $(26 \%)$ required new or increased need of vasopressor support following intubation (PIH). Rest of the patients responded to fluid boluses. Mechanical complications were relatively rare.

Table 3: Immediate complications of intubation

\begin{tabular}{|l|l|l|}
\hline Complication & Number & Percentage \\
\hline Hypoxia & 75 & $50 \%$ \\
SPO2 <88\% (mild) & 57 & $38 \%$ \\
SPO2 <80\% (moderate) & 9 & $6 \%$ \\
SpO2<70\% (severe) & 9 & $6 \%$ \\
\hline Hypotension (SBP <90mmHg) & 69 & $46 \%$ \\
Post intubation (new or increased) vasopressor & 39 & $26 \%$ \\
need & & \\
& & \\
\hline Cardiac arrest & 4 & $2 \%$ \\
Cardiac arrhythmia & 18 & $12 \%$ \\
\hline Mechanical complications & & \\
Oesophageal intubation & 9 & $6 \%$ \\
Regurgitation and aspiration & 9 & $6 \%$ \\
& & \\
\hline
\end{tabular}

Table 4: Univariate analysis on post intubation hypotension

\begin{tabular}{|c|c|c|c|c|}
\hline & $\begin{array}{l}\text { Total } \\
150\end{array}$ & $\begin{array}{l}\text { Stable } \\
\mathrm{N}-113\end{array}$ & $\begin{array}{l}\text { Unstable } \\
\mathrm{N}-39\end{array}$ & Pvalue \\
\hline $\operatorname{Age}(>60)$ & $42(28 \%)$ & $24(16 \%)$ & $18(12 \%)$ & 0.47 \\
\hline Gender (female) N (\%) & $63(42 \%)$ & $21(14 \%)$ & $42(28 \%)$ & 0.738 \\
\hline Pre intubation & & & & \\
\hline Oxygen saturation (<88\%) N (\%) & $75(50 \%)$ & $42(28 \%)$ & $33(22 \%)$ & .071 \\
\hline Systolic Blood pressure < & $45(30 \%)$ & $9(6 \%)$ & $36(24 \%)$ & $.000^{*}$ \\
\hline $90 \mathrm{mmHg} \mathrm{N}(\%)$ & $51(34 \%)$ & $15(10 \%)$ & $36(24 \%)$ & $.002^{*}$ \\
\hline Mean arterial blood pressure< & $27(18 \%)$ & $18(12 \%)$ & $9(6 \%)$ & .105 \\
\hline $65 \mathrm{mmHg} \mathrm{N}(\%)$ & $24(18 \%)$ & $3(4 \%)$ & $21(14 \%)$ & $.000^{*}$ \\
\hline GCS before intubation $(<8) \mathrm{N}(\%)$ & $75(50 \%)$ & $51(34 \%)$ & $24(16 \%)$ & .478 \\
\hline Airway support before intubation & $78(52 \%)$ & $24(16 \%)$ & $54(36 \%)$ & $.000^{*}$ \\
\hline $\mathrm{N}(\%)$ & $54(36 \%)$ & $15(10 \%)$ & $39(26 \%)$ & $.000^{*}$ \\
\hline $\begin{array}{l}\text { Respiratory support before } \\
\text { intubation N (\%) }\end{array}$ & & & & \\
\hline CVS Support before intubation $\mathrm{N}$ & & & & \\
\hline & & & & \\
\hline q SOFA (sore 3) & & & & \\
\hline Reason for intubation & & & & \\
\hline Patient newly admitted to ICU N & $42(28 \%)$ & $33(22 \%)$ & $9(6 \%)$ & .594 \\
\hline & $78(52 \%)$ & $51(34 \%)$ & $27(18 \%)$ & .456 \\
\hline $\begin{array}{l}\text { Patient deterioration } \mathrm{N}(\%) \\
\text { Failed trial of extubation } \mathrm{N}(\%)\end{array}$ & $9(6 \%)$ & $6(4 \%)$ & $3(2 \%)$ & .346 \\
\hline Propofol induction N (\%) & $51(34 \%)$ & $15(11 \%)$ & $36(23 \%)$ & $.000^{*}$ \\
\hline Non propofol induction N (\%) & $99(66 \%)$ & $98(86 \%)$ & $3(7 \%)$ & .478 \\
\hline Neuromuscular blockers & & & & \\
\hline Suxamethonium $\mathrm{N}(\%)$ & $126(84 \%)$ & $78(52 \%)$ & $48(32 \%)$ & .829 \\
\hline Atracurium N (\%) & $21(14 \%)$ & $15(10 \%)$ & $6(4 \%)$ & .667 \\
\hline Opioid & & & & \\
\hline Usage of Fentanyl & $114(76 \%)$ & $81(54 \%)$ & $33(22 \%)$ & .398 \\
\hline $\begin{array}{l}\text { Post intubation hypoxia } \\
\mathrm{SpO}_{2}<88 \% \mathrm{~N}(\%)\end{array}$ & $75(50 \%)$ & $12(8 \%)$ & $63(42 \%)$ & $.004^{*}$ \\
\hline $\begin{array}{l}\text { Development of mechanical } \\
\text { complication } \mathrm{N}(\%)\end{array}$ & $18(12 \%)$ & $3(2 \%)$ & $15(10 \%)$ & $.005^{*}$ \\
\hline $\begin{array}{l}\text { Lack of supervision during } \\
\text { intubation } \mathrm{N}(\%)\end{array}$ & $72(48 \%)$ & $24(16 \%)$ & $48(32 \%)$ & $.001^{*}$ \\
\hline
\end{tabular}

N- Number, Stable- not developed PIH according to study definition, Unstabledeveloped PIH according to study definition.

Patients were stratified to two groups depending on whether they developed PIH or not. Univariate analysis was performed on collected variables. Some variables were made binary variables, for example, age, systolic blood pressure (SBP), oxygen saturation,mean arterial pressure (MAP), GCS, induction agents, NMB, development of mechanical complications (oesophageal intubation and regurgitation and aspiration) to get reasonable numbers for analysis without harming the accuracy of data.

Pre intubation hypotension (MAP $<65 \mathrm{mmHg}$, $\mathrm{SBP}<90 \mathrm{mmHg}$ ), airway support before intubation, cardiovascular support before intubation, higher qSOFA score, usage of propofol, mechanical complication of intubation, post intubation hypoxia and lack of intubation supervision shows significant association for PIH.

Multivariate analysis was applied on the above significant associations, after adjusting to age and illness severity by qSOFA score. Significant factors are shown in Table 5. When controlled for the other variables the chances of developing PIH among patients who had propofol was 17.38 times higher than having other induction agents like midazolam andketamine and this is statistically significant.

Table 5: Factors associated with development of post intubation hypotension multivariate analysis

\begin{tabular}{|l|l|l|l|}
\hline Variable & P value & $\begin{array}{l}\text { Odds } \\
\text { ratio }\end{array}$ & $95 \% \mathrm{Cl}$ \\
\hline Usage of induction agent (propofol) & 0.000 & 17.38 & $4.18-72.30$ \\
\hline Usage of neuromuscular blocker & 0.003 & 0.097 & $0.021-0.459$ \\
\hline $\begin{array}{l}\text { Cardiovascular support before } \\
\text { intubation }\end{array}$ & 0.000 & 0.038 & $0.005-0.134$ \\
\hline Airway support before intubation & 0.000 & 0.012 & $0.001-0.114$ \\
\hline $\begin{array}{l}\text { Mechanical complication during } \\
\text { intubation }\end{array}$ & 0.000 & 3.82 & $0.603-22.41$ \\
\hline Post intubation hypoxia (<88\%) & 0.033 & 3.31 & $1.099-9.989$ \\
\hline
\end{tabular}

Other significant associations in this study shown in Table 6. Post intubation mechanical complications were significantly associated with place of intubation, number of laryngoscopy attempts, grade of laryngoscopy view and degree of training of intubator. 
Table 6: Significant associations- univariate analysis

\begin{tabular}{|l|l|}
\hline Association & P value \\
\hline $\begin{array}{l}\text { Pre intubation hypoxia * development of post } \\
\text { intubation hypoxia }\end{array}$ & 0.004 \\
\hline Post intubation mechanical complications & \\
Place of intubation & 0.03 \\
Number of laryngoscopic attempts & 0.04 \\
Higher laryngoscopic view & 0.006 \\
Training of intubating doctor & 0.003 \\
\hline
\end{tabular}

\section{Discussion}

Success rate of intubation in this study was $100 \%$ and the complication rates are comparable with published reports from the developed world. This study has covered all ICUs in NHSL including $\mathrm{A} \& \mathrm{E}$, catheter care laboratory and medical and surgical wards. Even though the success rates were high there was significant room for improvement.

Preoxygenation is an essential part in rapid sequence induction for intubation to improve the safe period of apnoea specially in critically ill patients. In this study $36 \%$ of patients were hypoxaemic before intubation and all patients had oxygen therapy before intubation as either face mask oxygen or non-invasive ventilation. Practice of preoxygenation wasgood in this study $(98 \%)$. In literature the rates of preoxygenation varied from $80 \%$ to $95 \% \%^{2,4,8}$ Application of cricoid pressure is controversial as no proven benefit. It was $66 \%$ in this sample and clearly lower than the other studies, which was above $80 \%{ }^{2,3}$ It was difficult to ascertain the reasons for it, as it wasn't analysed. Overall, the adherence to evidence-based practices is satisfactory in this study sample.

Usage of capnography and the availability of difficult intubation equipment is an integral part in intubation of critically ill. Itis emphasized by NAP4 and guidelines provided by College of Anaesthesiologists and Intensivists of Sri Lanka. Availability of difficult airway trolley during the intubation was $88 \%$ and capnography use was $68 \%$. Multicentre study in Scotland found their adherence with capnography in critically ill was only $54 \% .{ }^{2}$ Reason behind non-usage may be the lack of equipment in certain settings in NHSL. This is clearly needed to be addressed to reduce the complication rates associated with emergency intubation.
Commonly used induction agent in study sample was midazolam (58\%) which is clearly higher than in the developed world. Usage of propofol was low at $32 \%$ and is almost half the frequency of usage in other studies. ${ }^{2,4}$ Only opioid used in this setting was fentanyl, while alfentanil, fentanyl and remifentanil was recorded in other studies. ${ }^{2,4}$ Suxamethonium was used almost exclusively in NHSL (84\%), the other NMB agent was atracurium. Rocuronium was the commonest in the literature. Since practices and availability of drugs is quite different in Asian and European countries this difference cannot be compared.

Intubation at first attempt was $68 \%$ and only $10 \%$ of patients needed a third attempt for intubation. Other studies have found first attempt success rates $90 \%$ to $63 \%$ and around $12 \%$ needing three or more attempts. ${ }^{2,4,8,9}$ It is clearly encouraging as only few patients needed a third attempt at intubation and there were no failed intubations.

Common complications are two streamed, physiological and mechanical. Percentages of hypoxia $(50 \%)$, cardiac arrest $(2 \%)$ were comparable to literature, with relatively lower rates of moderate to severe hypoxia $2 \%-4 \%{ }^{8,}$

However, incidence of post intubation hypoxia in this sample was higher than the study done in France, where they had a clear protocol for intubation of critically ill and practiced preoxygenation with positive pressure ventilation. ${ }^{1}$ In this study, adherence to preoxygenation was quite good, but there was a significant association between pre intubation hypoxia anddevelopment of post intubation hypoxia.

Mechanical complications were only (6\%) in this study, which is agreeing with the multi-centre study in Scotland. However, in other literature reported incidence was 1.3 to $9.7 .^{1,2-4,16}$ There was clear association between mechanical complications and place of intubation, higher incidence was found in out of ICU intubations. Other significant factors that showed an association were number of intubation attempts, grade 4 laryngoscopy view and level of training of intubator. Thus, the low rate in this study may be reflecting the fact that higher percentage intubation was done by doctors with formal anaesthesia training (84\%), most of the intubations were performed in the ICUs $(68 \%)$ 
and rates of first attempt intubations were high as 68. PIH is a common incident in intubation in critically ill. It was $26 \%$ according to study definition in this study and is comparable with studies done in other parts of the world, which used the same definition for post intubation hypotension. ${ }^{7,10}$ Post intubation hypotension is associated with increased mortality and morbidity in ICUs. ${ }^{1,5,6,12,15,16,17}$ Associated factors differ from each study as there is no universal definition for PIH. Study populations and study settings were differ between studies making comparison impossible. ${ }^{1,5,6,12,15,16,17}$ On univariate analysis of this sample, pre intubation low SBP, low MAP, higher qSOFA score, pre intubation airway support, cardiovascular support, propofol induction, post intubation hypotension, mechanical complications during intubation and degree of supervision were significantly associated with PIH.

When controlled for other variables the odds of having PIH among post-intubation hypoxaemic patients was 3.314 times higher than the odds of having PIH among non-hypoxaemic patients and this was statistically significant. The chances of developing PIH in patients who developed mechanical complication was 3.82 times higher than that of patients who did not develop mechanical complication $(\mathrm{P}<0.001)$.

Similarly, propofol induction increased the odds of developing hypotension. The odds ratio was 17.38 compared to the other agents. In this study the agents that were being compared were ketamine and midazolam.

A study done in USA (sample size 147), documented three risk factors for PIH following multivariate analysis, those were pre intubation hypotension, administration of neuromuscular blockers and intubation complications. ${ }^{10}$ In the same study there was no significant association of $\mathrm{PIH}$ and induction agent. They suggested that if it were a bigger sample size, there might be a significant association between induction agent and hypotension. ${ }^{10}$ Multicentred cohort done in Canada failed to identify a significant association between propofol and PIH even though it was used in $68 \%$ of patients in their sample. ${ }^{17}$

This difference in findings may be due to differences in the population as well as the practices in two different regions of the world. The per kilogram dose of propofol may influence this finding, but the doses were not analysed in this study.

Interestingly pre intubation airway support, cardiovascular support and usage of suxamethonium show significant protective effect towards the development of post intubation hypotension. When patient already had resuscitation with fluid, supportive inotropes and airway support before the intubation this might reduce the deleterious effect of induction agent and laryngoscopy stimulation. Retrospective cohort study done on this topic found that diagnosis of sepsis has protective effect for post intubation hypotension, their data demonstrated that this cohort of patients received more intravenous fluids than the other patients before emergency intubation. ${ }^{10}$

In the above-mentioned study, researchers found a significant association between PIH and usage of NMB during intubation. This study shows a total controversy to that finding. In Sri Lanka emergency intubations are mainly done using suxamethonium as rocuronium is not freely available. Only other commonly used NMB is atracurium. Thus, this result may reflect the effect between those two NMB agents. Thus, controversy may be a reflect of different agent being used in two different settings.

\section{Conclusion}

There is high success rate of intubation with no recorded failed intubation during the study period in critically ill patients in NHSL. There is higher percentage $(84 \%)$ of involvement of formally trained doctor in the process of intubating critically ill and more than half of intubations are directly supervised by a senior doctor during the procedure. Adherence to preoxygenation was as high as $98 \%$ but inadequate usage of difficult airway trolley (88\%) and capnography (68\%) was observed. Even though the mechanical complication rates of intubations are low, there isa high rate of post intubation hypoxia and hypotension. Identified significant associated factors for PIH werepropofol induction, post intubation hypoxaemia and mechanical complications. Pre intubation airway and cardiovascular support and usage of suxamethonium had shown protective effect towards the development of PIH. 


\section{References}

1. Schwartz DE, Matthay MA, Cohen NH. Death and other complications of Emergency Airway

Management in Critically ill Adults.

Anaesthesiology 1885;82:367-376

https://doi.org/10.1097/00000542-19950200000007

PMid:7856895

2. Simpson GD, Ross MJ, McKeown DW, Ray DC. Tracheal intubation in the critically ill: a multicenter national study of practice and complications. British Journal of Anaesthesia 2012;108 (5): 792799

https://doi.org/10.1093/bja/aer504

PMid:22315326

3. Bowles TM, Freshwater-Turner DA, Janssen DJ, Peden CJ, on behalf of the RTIC Severn Group. Out-of-theatre tracheal intubation: prospective multicentre study of clinical practice and adverse events. Br J Anaesth 2011; 107: 687-92

https://doi.org/10.1093/bja/aer251

PMid:21828342

4. Griesdale DE, Bosma TL, Kurth T, Isac G, Chittock DR. Complications of endotracheal intubation in the critically ill. Intensive Care Med 2008; 34: 1835-42

https://doi.org/10.1007/s00134-008-1205-6 PMid:18604519

5. Heffner AC, Swords D, Kline JA, Jones AE. The frequency and significance of post intubation hypotension during emergency airway management. J Crit Care, 2012; 27: 417e9-13 8.

https://doi.org/10.1016/j.jcrc.2011.08.011 PMid:22033053

6. Smischney NJ, Ricter BD, Hoeft CC et al. Association of post-intubation hemodyanmic instability in an adult icu with in-hospital mortality and icu length of stay. Am J Respir Crit Care Med, 2014; 189: A4558

7. Smischney NJ, Demirci O, Ricter BD et al. Vasopressor use as a surrogate for postintubation hemodynamic instability is associated with inhospital and 90-day mortality. BMC Res Notes, 2015; 8: 445.

https://doi.org/10.1186/s13104-015-1410-7 PMid:26374289 PMCid:PMC4572685

8. Jaber S, Amraoui J, Lefrant JY et al. Clinical practice and risk factors for immediate complications of endotracheal intubation in the intensive care unit: a prospective multiple-center study. Crit Care Med 2006; 34: 2355-61

https://doi.org/10.1097/01.CCM.0000233879.58720 .87

PMid:16850003

9. Mort TC. Emergency tracheal intubation: complications associated with repeated laryngoscopic attempts. AnesthAnalg 2004; 99: 607-13
https://doi.org/10.1213/01.ANE.0000122825.04923. $\underline{15}$

PMid:15271750

10. Smischney NJ, Demirc O, Diedrich DA, David $\mathrm{W}$ et al. Incidence of and Risk Factors For PostIntubation Hypotension in the Critically Ill. 2016; 22: 346-355

11. Difficult Airway Society. Rapid sequence induction-guidelines: rapid sequence induction, non-pregnant, no predicted difficulty. Available from http:/www.das.uk.com/guidelines/rsi.html 12. Jaber S, Jung B, Corne P, et al. An intervention to decrease complications related to endotracheal intubation in the intensive care unit: a prospective, multiple-center study. Intensive Care Med 2010; 36: 248-55

https://doi.org/10.1007/s00134-009-1717-8 PMid:19921148

13. Mort TC. Preoxygenation in critically ill patients requiring emergency tracheal intubation. Crit Care Med 2005; 33: 2672-5

https://doi.org/10.1097/01.CCM.0000187131.67594 $.9 \mathrm{E}$

PMid:16276196

14. Mort TC, Waberski BH, Clive J. Extending the preoxygenation period from 4 to 8 mins in critically ill patients undergoing emergency intubation. Crit Care Med 2009; 37: 68-71

https://doi.org/10.1097/CCM.0b013e318192845e PMid:19050620

15. Martin LD, Mhyre JM, Shanks AM, Tremper KK, Kheterpal S. 3423 emergency tracheal intubations at a University hospital: airway outcomes and complications. Anesthesiology 2011; 114: $42-8$ https://doi.org/10.1097/ALN.0b013e318201c415 PMid:21150574

16. Leibowitz AB. Tracheal intubation in the intensive care unit: extremely hazardous even in the best of hands. Crit Care Med 2006; 34: 2497-8 https://doi.org/10.1097/01.CCM.0000235993.47514 $.8 \mathrm{~F}$

PMid:16921325

17. Green RS, Turgeon AF, McIntyre LA et al. Doucette. Postintubation hypotension in intensive care unit patients: A multi-centre cohort study; journal of critical care 2015; 30(5):1055-60. PMID:26117220

https://doi.org/10.1016/j.jcrc.2015.06.007 